\title{
Sonographic assessment of pregnancy co-existing with uterine leiomyoma in Owerri, Nigeria
}

\author{
*Eze $\mathrm{CU}^{1}$, Odumeru EA ${ }^{2}$, Ochie $\mathrm{K}^{1}$, Nwadike $\mathrm{UI}^{1}$, Agwuna $\mathrm{KK}^{3}$
}

1. Department of Medical Radiography and Radiological Sciences, Faculty of Health Sciences and Technology, University of Nigeria, Enugu Campus, Enugu State, Nigeria

2. Department of Radiology, Federal Medical Centre, Owerri, Nigeria.

3. Department of Radiation Medicine, Faculty of Medicine, University of Nigeria Teaching Hospital, Ituk/ Ozalla, Enugu, Nigeria.

\begin{abstract}
Background: Uterine myomas co-existing with pregnancy could cause obstetric complications.

Objectives: To assess sonographically the frequency of occurrence and effect of uterine myomas co-existing with pregnancy. Methods: A longitudinal study was conducted during a period of 23 months. A convenience sample of 816 consecutive consenting pregnant women who met the inclusion criteria was evaluated during routine prenatal ultrasound scan. The women were referred for prenatal sonography. One hundred of the subjects who had myoma co-existing with pregnancy and another 100 subjects without myoma were selected for follow-up. These groups were followed up till delivery and obstetric complications and outcomes were documented. Any changes in size and growth rate of myoma were documented. Results: Subjects with myoma co-existing with pregnancy were $12.3 \%$. This was commoner with increasing maternal age. An increase was observed in myoma mean size from $60 \mathrm{~mm}$ to $63 \mathrm{~mm}$ from the $1^{\text {st }}$ scan sequence to the $2^{\text {nd }}$ scan sequence and a reduction from $63 \mathrm{~mm}$ to $59 \mathrm{~mm}$ in the $3^{\text {rd }}$ scan sequence. Myoma growth rate was $0.667 \mathrm{~mm}$ per week. Myomas in pregnancy especially large ones caused more complications during delivery when compared to pregnancies without myomas. Conclusion: Routine sonography is important in pregnancy management of uterine myomas co-existing with pregnancy. Keywords: Routine sonography; uterine myoma, pregnancy, obstetric complications. African Health Sciences 2013; 13(2):453 - 460 http://dx.doi.org/10.4314/ahs.v13i2.36
\end{abstract}

\section{Introduction}

Uterine leiomyoma, also known as uterine fibroid is a mass of compacted smooth muscle and fibrous tissue diagnosed in about $20 \%$ to $25 \%$ of women older than 25 years. ${ }^{1}$ Aetiologies of uterine leiomyomas are unknown but several predisposing factors have been identified including age (late reproductive years), African-American ethnicity, nulliparity, obesity and genetics. ${ }^{2}$ It is seven times commoner in blacks compared to Caucasians ${ }^{3}$ and can grow so large to cause negative impact on obstetric outcome if co-existing with pregnancy. Estrogen is recognized as promoter of tumour growth. During pregnancy, the influx of this hormone is said to have effects on the co-existing

\begin{tabular}{|l|}
\hline *Correspondence author: \\
Dr. Charles Ugwoke Eze \\
Department of Medical Radiography and Radiological \\
Sciences \\
Faculty of Health Sciences and Technology \\
University of Nigeria, Enugu Campus \\
Enugu State, Nigeria \\
Phone: +2348052805214 \\
Email:ugwoke.eze@unn.edu.ng \\
ezecharlesu@yahoo.com
\end{tabular}

African Health Sciences Vol 13 Issue 2 June 2013 myomas. Uterine myomas usually develop before pregnancy and are usually discovered during ultrasound examination particularly in patients who present with symptoms.

There are five common types of uterine fibroids. They are identified by where they are located in the uterus. Subserosal fibroids develop in the outer portion of the uterus and grow outward. These fibroids can be painful if they are large and press on the other organs. They usually do not affect a woman's menstrual flow. Submucous fibroids develop just under the lining of the uterine cavity. These are the least common types of fibroid. They often cause very heavy, long menstrual periods. Pendunculated uterine fibroid occurs when the fibroid grows on a stalk. These can grow in the uterine cavity or on the outside of the uterus. Intramural fibroid develops and localizes within the myometrium. During pregnancy, retro-placental fibroid can be seen behind the placenta where they may exert pressure on it.

Uterine fibroids also have implications in non-pregnant women of reproductive age. About 1 in every 15 women with infertility has fibroids, 
but the fibroids are usually innocent bystanders. ${ }^{4}$ They cause only $2 \%$ to $3 \%$ of cases of infertility. Fibroids that block one or both of the fallopian tubes may prevent sperm from fertilizing an egg while fibroids that fill the uterine cavity may block implantation of a newly fertilized egg. ${ }^{5}$

Based on risk factors for myoma development which include diet, race, geographical and socio-economic differences ${ }^{6-9}$, our locality has a greater susceptibility of rapid myoma growth. Therefore, it is being advocated that routine ultrasound investigation should be encouraged in all pregnancies in order to detect myomas or any other lesions early enough for better obstetric management. ${ }^{10}$

Ultrasound and magnetic resonance imaging (MRI) are modalities of choice for diagnosis of uterine fibroids. ${ }^{11}$ Location, size, number and extent of myoma penetration into the myometrium are usually evaluated by MRI without the use of gadolinium contrast. The drawbacks of MRI in evaluation of uterine fibroids include high cost and low accessibility compared to ultrasound which is simple, non- invasive, affordable and more readily available. X-radiation based modalities are rarely used in pregnancy due to radiation hazards to the fetus.

This study is aimed at assessing uterine leiomyomas co-existing with pregnancy and associated obstetric complications by routine prenatal sonography.

\section{Methods}

This was a longitudinal study conducted during a period of 23 months. The study was carried out at departments of Radiology, and Obstetrics and Gynaecology, Federal Medical Centre, Owerri, Nigeria from August, 2009 to July, 2011. Ethical approval was obtained from the Research Ethics Committee of the hospital before commencement of the study. A convenience sample of 816 consecutive consenting pregnant women who met the inclusion criteria was evaluated during routine prenatal ultrasound scan. The women were attending antenatal clinic in the hospital and were referred to have prenatal sonography. Informed consent was obtained from subjects who met the inclusion criteria before being enlisted in the study. One hundred of the subjects who had myoma co-existing with pregnancy and another 100 subjects without myoma (control group) were selected for follow-up. The two groups were followed up till delivery and obstetric complications and outcomes were documented appropriately. Inclusion criterion was singleton pregnancy of between 6 weeks and 40 weeks gestational age. Exclusion criteria were non gravid women with myoma, ectopic pregnancy and multiple pregnancies. Multiple pregnancies are known to be high-risk pregnancies with a number of complications developing which may not be necessarily associated with co-existing myoma.

Subjects in whom myomas were identified were rescanned thrice at $3-6$ weeks ( 4.5 weeks mean interval) before delivery to document any changes in size and growth velocity of myoma.

Ultrasound Equipment: The subjects were examined with S1-400, SS1- 600 (Siemens AG, Germany), and GE 8900 (General Electric Company, USA) real time ultrasound machines with $3.5 \mathrm{MHz}, 5.0 \mathrm{HMz}$ and $7.5 \mathrm{MHz}$ curvilinear and linear transducers respectively. The choice of these probes was based on varying degrees of penetration needed. Validity and reliability of the equipment were tested prior to the study through pilot study and quality assurance. The entire abdomino-pelvic area was scanned in both longitudinal and transverse planes using transducer manipulations ${ }^{4}$ to assess fetal viability, presentation, gestational age (GA), expected date of delivery (EDD), and presence, location and size of co-existing myoma. Myomas were measured in three dimensions in millimetre (height, width and length) to determine the mean size. Also location/type of myoma was determined in each subject and documented.

Demographic and clinical details of the subjects as written in the ultrasound request forms were extracted for use in the study. These include patient age, routine scan, unsure date (in the initial scan), and clinical impressions such as malpresentation, premature rupture of membrane (PROM), severe pelvic pain, bleeding, missed abortion/intrauterine death (IUD), intrauterine growth restriction (IUGR) (in subsequent scans).

\section{Statistical analysis}

Data collected were analysed using the Statistical Package for Social Sciences (SPSS) version 19.0 (Chicago, Illinois, USA). Both descriptive and inferential statistics were carried out. For the purpose of inference, statistical significance was considered at $\mathrm{p}<0.05$. Incidence of myoma co-existing with pregnancy was expressed as percentage of total number of subjects evaluated. Growth velocity was calculated using simple descriptive statistics. 


\section{Results}

Table 1 shows the age distribution of subjects and distribution of fibroid among the subjects according to age. The mean age of the subjects with myoma was calculated from the raw data to be $31.6 \pm 4.5$ years while the mean age for subjects without myoma was $29.1 \pm 5.5$ years. An occurrence of $12.3 \%$ for myoma co-existing with pregnancy was found. The occurrence of fibroid was significantly more in older subjects; $25-39$ years $(\mathrm{p}<0.05)$.

Table 1: Age distribution of subjects and distribution of fibroid among the subjects according to age

\begin{tabular}{llllll}
\hline \multirow{2}{*}{$\begin{array}{l}\text { Age group } \\
\text { (years) }\end{array}$} & \multicolumn{4}{c}{ Pregnancy status (\%) } & \\
\cline { 2 - 5 } 15-19 years & 0 & $(0.0 \%)$ & 29 & $(3.6 \%)$ & $29(3.6 \%)$ \\
20-24 years & 5 & $(0.6 \%)$ & 126 & $(15.4 \%)$ & $131(16.0 \%)$ \\
25-29 years & 30 & $(3.7 \%)$ & 235 & $(28.8 \%)$ & $265(32.5 \%)$ \\
30-34 years & 40 & $(4.9 \%)$ & 210 & $(25.7 \%)$ & $250(30.6 \%)$ \\
35-39 years & 17 & $(2.1 \%)$ & 86 & $(10.5 \%)$ & $103(12.6 \%)$ \\
40-44 years & 8 & $(1.0 \%)$ & 30 & $(3.7 \%)$ & $38(4.7 \%)$ \\
Total & 100 & $(12.3 \%)$ & 716 & $(87.7 \%)$ & $816(100.0 \%)$ \\
\hline
\end{tabular}

Note: The mean age of the subjects with myoma was calculated to be $31.6 \pm 4.5$ years while the mean age of the group without myoma was $29.1 \pm 5.5$ years. These were calculated from the raw data.

Figure 1 shows that pedunculated subserous and retroplacental myomas had the lowest occurrences compared to other types of myoma. Majority of the myomas co-existing with pregnancy were multiple $(51.0 \%, \mathrm{n}=51)$ while single myomas constituted $49.0 \%(\mathrm{n}=49)$.

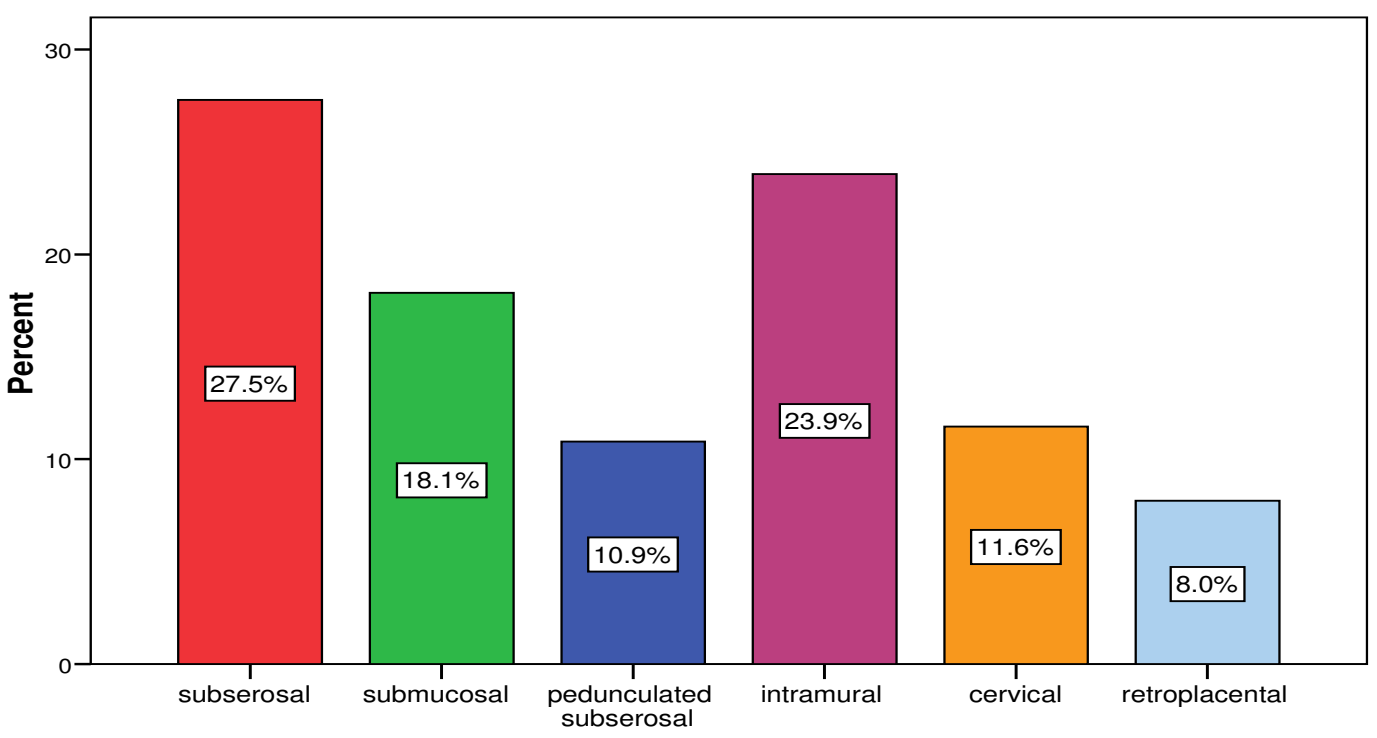

Figure 1: Types of fibroid observed in pregnant women studied

Table 2 reveals that there was an increase in aggregate myoma mean size of $60 \mathrm{~mm}$ to $63 \mathrm{~mm}$ between the first scan and the second scan. A 3 to 6 weeks interval of scan (mean $=4.5$ weeks) was allowed. The growth rate was calculated to be $0.667 \mathrm{~mm}$ per week.
Table 3 shows that there was weak but statistically significant relationship between the mean size of myoma and GA ( $\mathrm{p}=0.01)$. No significant relationship was observed between myoma mean size and maternal age $(p=0.52)$. 
Table 2: Mean size of myoma in the 3 scan sequences

\begin{tabular}{cccccccccc}
\hline & & $\begin{array}{c}\text { Aggregat } \\
\mathrm{e} \\
\text { / Mean }\end{array}$ & Median & Minimum & Maximum & SD & $>75$ & $<25$ & 25 to 75 \\
\hline Mean size of $1^{\text {st }}$ scan & $(\mathrm{mm})$ & 60 & 55.8 & 10 & 140 & 28 & $28.3 \%$ & $8.0 \%$ & $63.8 \%$ \\
Mean size of $2^{\text {nd }}$ scan & $(\mathrm{mm})$ & 63 & 58.1 & 15 & 159 & 29 & $31.2 \%$ & $5.8 \%$ & $63.0 \%$ \\
Mean size of $3^{\text {rd }}$ scan & $(\mathrm{mm})$ & 59 & 51.0 & 9 & 139 & 29 & $27.2 \%$ & $4.9 \%$ & $67.9 \%$ \\
\hline
\end{tabular}

Table 3: Correlation of mean size of fibroid, gestational age and maternal age

\begin{tabular}{llll}
\hline & & $\begin{array}{l}\text { Mean size of } \\
\text { fibroid }\end{array}$ \\
\hline Gestational age (weeks) & Pearson's correlation & Coefficient & $0.111^{*}$ \\
& Pearson's correlation & p-value & 0.037 \\
Coefficient & 0.035 \\
Maternal age & & p-value & 0.515 \\
(years) & & \\
\hline
\end{tabular}

* Correlation is significant at the 0.05 level (2-tailed)

Table 4 shows that a significant majority of patients with myoma co-existing with pregnancy $(65 \%, \mathrm{n}=$ 65) had complications during the course of pregnancy while $35 \%(\mathrm{n}=35)$ had no complications $(\mathrm{p}<0.05)$. The occurrence of obstetric complications such as abortion or fetal death was observed in all the age group except women between the age groups of $15-19$ years and $20-24$ years. The 15-19 years age group had no complications at all. The least complication observed was premature rupture of membrane $(\mathrm{PROM})$ which accounted for only $2 \%(n=2)$. Subjects without myoma who were followed up also had obstetric complications seen in all the age groups as shown in table 5. Twenty one subjects $(21 \%)$ without myoma co-existing with pregnancy had complications while $79 \%$ of the subjects $(\mathrm{n}=79)$ had no complications. The commonest complication noted in both groups was pelvic pains as shown in tables 4 and 5 while the least complication was PROM.

\section{Table 4: Obstetric complications observed in subjects with myoma according to age}

\begin{tabular}{|c|c|c|c|c|c|c|c|c|}
\hline \multirow[b]{2}{*}{$\begin{array}{l}\text { Age group } \\
\text { (years) }\end{array}$} & \multicolumn{5}{|c|}{ Obstetric Complications } & \multirow[b]{2}{*}{ IUGR } & \multirow[b]{2}{*}{$\begin{array}{c}\text { No } \\
\text { Complication } \\
\mathrm{s}\end{array}$} & \multirow[b]{2}{*}{ Total } \\
\hline & $\begin{array}{l}\text { Abortion/fetal } \\
\text { death/bleeding }\end{array}$ & $\begin{array}{l}\text { Malpres- } \\
\text { entation }\end{array}$ & PROM & $\begin{array}{l}\text { Pelvic } \\
\text { pains }\end{array}$ & $\begin{array}{l}\text { Preterm } \\
\text { delivery }\end{array}$ & & & \\
\hline $15-19$ & $0(0 \%)$ & $0(0 \%)$ & $0(0 \%)$ & $0(0 \%)$ & $0(0 \%)$ & $0(0 \%)$ & $0(0 \%)$ & \\
\hline $20-24$ & $0(0 \%)$ & $0(0 \%)$ & $0(0 \%)$ & $0(0 \%)$ & $0(0 \%)$ & $1(1 \%)$ & $4(4 \%)$ & $5(5 \%)$ \\
\hline $25-29$ & $10(10 \%)$ & $3(3 \%)$ & $2(2 \%)$ & $3(3 \%)$ & $3(3 \%)$ & $3(3 \%)$ & $6(6 \%)$ & $30(30 \%)$ \\
\hline $30-34$ & $12(12 \%)$ & $1(1 \%)$ & $0(0 \%)$ & $9(9 \%)$ & $0(0 \%)$ & $0(0 \%)$ & $16(16 \%)$ & $40(40 \%)$ \\
\hline $35-39$ & $4(4 \%)$ & $1(1 \%)$ & $0(0 \%)$ & $2(2 \%)$ & $1(1 \%)$ & $1(1 \%)$ & $9(9 \%)$ & $17(17 \%)$ \\
\hline $40-44$ & $7(7 \%)$ & $0(0 \%)$ & $0(0 \%)$ & $1(1 \%)$ & $0(0 \%)$ & $0(0 \%)$ & $0(0 \%)$ & $8(8 \%)$ \\
\hline Total & $33(33 \%)$ & $5(5 \%)$ & $2(2 \%)$ & $15(15 \%)$ & $4(4 \%)$ & $5(5 \%)$ & $35(35 \%)$ & $\begin{array}{l}100 \\
(100 \%)\end{array}$ \\
\hline
\end{tabular}

Figure 2 shows that some patients with myoma size of $21 \mathrm{~mm}$ or bigger had Caesarean Section (CS) before the onset of labour, with the proportion increasing with increasing size of myoma. Patients with myoma size of 1-20 $\mathrm{mm}$ had spontaneous vaginal delivery (SVD). 


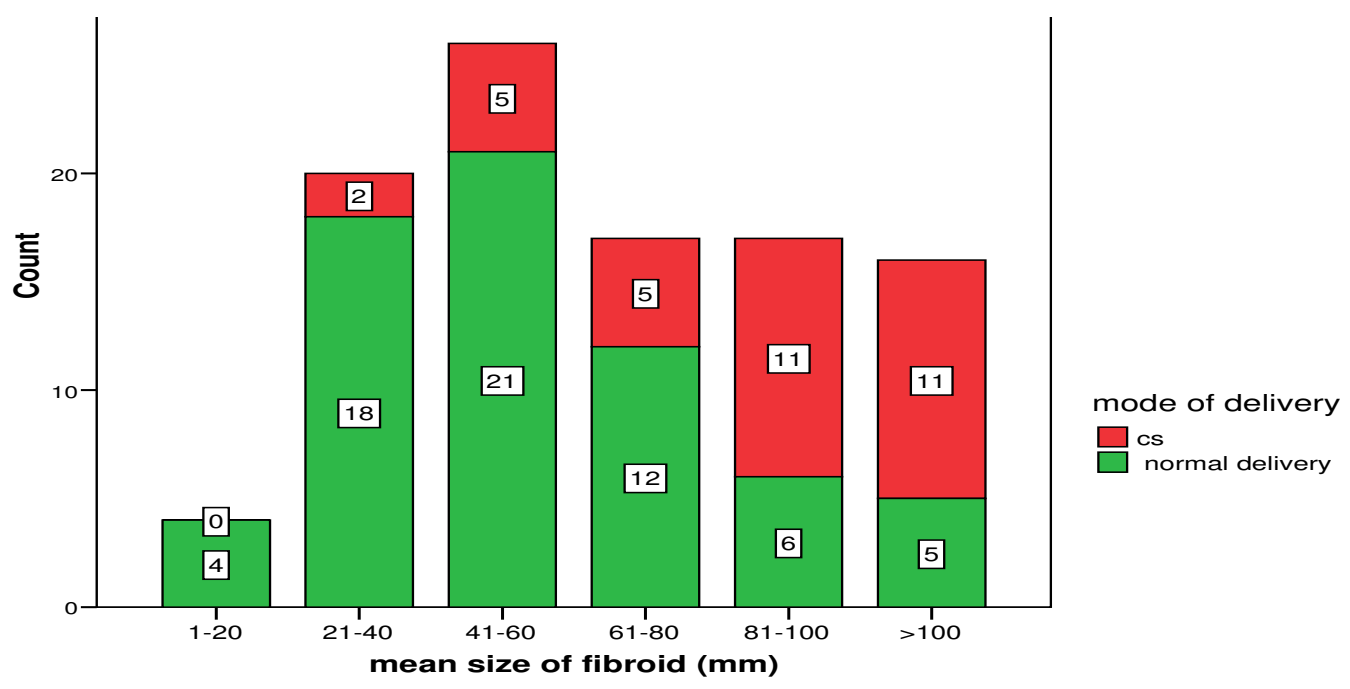

Figure 2: Co-existing myoma size and mode of delivery

Table 5: Obstetric complications in subjects without myoma according to age

\begin{tabular}{lllllllll}
\hline & \multicolumn{7}{c}{ Obstetric Complications } & \\
\cline { 2 - 7 } $\begin{array}{l}\text { Age group } \\
\text { (years) }\end{array}$ & $\begin{array}{l}\text { Abortion/fetal } \\
\text { death/bleeding }\end{array}$ & $\begin{array}{l}\text { Malpres- } \\
\text { entation }\end{array}$ & PROM & $\begin{array}{l}\text { Pelvic } \\
\text { pains }\end{array}$ & $\begin{array}{l}\text { Preterm } \\
\text { delivery }\end{array}$ & IUGR & $\begin{array}{l}\text { No } \\
\text { complic- } \\
\text { ations }\end{array}$ & Total \\
\hline $15-19$ & $0(0 \%)$ & $0(0 \%)$ & $0(0 \%)$ & $1(1 \%)$ & $1(1 \%)$ & $0(0 \%)$ & $5(\%)$ & $7(7 \%)$ \\
$20-24$ & $0(0 \%)$ & $1(1 \%)$ & $0(0 \%)$ & $2(2 \%)$ & $0(0 \%)$ & $0(0 \%)$ & $14(14 \%)$ & $17(17 \%)$ \\
$25-29$ & $1(1 \%)$ & $0(0 \%)$ & $0(0 \%)$ & $2(2 \%)$ & $0(0 \%)$ & $0(0 \%)$ & $26(26 \%)$ & $29(29 \%)$ \\
$30-34$ & $2(2 \%)$ & $0(0 \%)$ & $1(1 \%)$ & $0(0 \%)$ & $0(0 \%)$ & $0(0 \%)$ & $21(21 \%)$ & $24(24 \%)$ \\
$35-39$ & $0(0 \%)$ & $2(2 \%)$ & $1(1 \%)$ & $0(0 \%)$ & $1(1 \%)$ & $1(1 \%)$ & $9(9 \%)$ & $14(14 \%)$ \\
$40-44$ & $0(0 \%)$ & $0(0 \%)$ & $0(0 \%)$ & $2(2 \%)$ & $1(1 \%)$ & $2(2 \%)$ & $4(4 \%)$ & $9(9 \%)$ \\
Total & $3(3 \%)$ & $3(3 \%)$ & $2(2 \%)$ & $7(7 \%)$ & $3(3 \%)$ & $3(3 \%)$ & $79(79 \%)$ & $100(100 \%)$ \\
\hline
\end{tabular}

\section{Discussion}

The present study shows an incidence of 12.3\% myoma co-existing with pregnancy. Myoma coexisting with pregnancy was commoner in the older women. This may be due to the fact that women in our locality are delaying childbearing to their thirties perhaps as a result of increasing need to acquire meaningful Western education. Increasing age is a risk factor for fibroid growth. ${ }^{12}$ Several studies on the incidence of myoma have been carried out in different localities by different researchers around the world and they observed that the incidences obtained varied with the sample size and population studied. In Poland for instance, Batoniak et $\mathrm{al}^{4}$ evaluated 670 women and obtained an incidence of $24 \%$. They noted that myoma is commoner in women of 25 years of age and above. The findings of those researchers suggest that women aged 25 years and over stand the risk of having myoma coexisting with their pregnancy. These finding regarding incidence and peak age for myoma development differ from the findings of the present study and may be due to racial variations. In Germany, Bosev and Dimitrov ${ }^{13}$ found that solitary myomas were dominant over multiple myomas. Their finding corroborated the report of Exacoustos and Rosati ${ }^{14}$ in Italy. Contrary to this, however, in the present study, multiple myomas were slightly more than single myoma. Multiple myomas in pregnancy may pose more serious complications such as preterm birth and miscarriage.

Govan et $\mathrm{al}^{15}$ classified myomas into types based on their location within the uterus and found that intramural myomas account for about $70 \%$ of all the types. Gross and Fleischer ${ }^{18}$ found $10 \%$ of myomas in their study to be submucous and less than $10 \%$ to be cervical, while Tsuda and Gross ${ }^{1}$ found the occurrence of subserous myomas to be as high as $20 \%$ and retroplacental myomas to be 
less than 5\%. In this study subserous fibroid had the highest incidence amongst other types/location corroborating the findings of Bosev and Dimitrov. ${ }^{13}$ Subserous myomas grow externally towards the serosal covering of the uterus which causes the uterus to be bumpy. As a result, most of them are clinically palpable and the smaller ones are usually asymptomatic. However, large subserous myomas may be symptomatic; they may press on surrounding structures / organs causing pelvic pain. They seldom affect menstrual flow or cause infertility. The location of myoma in relation to the uterus and placenta has a lot of implications and may serve as a pointer to obstetric management and mode of delivery.

The present study reveals changes in size of myoma during pregnancy. The rate of growth rate of myomas from first trimester to second trimester was $0.667 \mathrm{~mm}$ per week. This finding agrees with that of Bosev and Dimitrov ${ }^{13}$ who studied the changes in the myoma size during pregnancy in the first, second and third trimesters. There was significant correlation established between the myoma size and GA in present study but no relationship with maternal age. This implies greater risk of complications as pregnancy advances. In the present study, a reduction in myoma size was noted in the 3rd trimester (3rd scan sequence) and this appears to be inconclusive due to the number of subjects who later had abortion. Several studies ${ }^{17-20}$ opined that myoma cell hypertrophies during pregnancy and later shrinks in late pregnancy and this probably explains the observed fibroid growth trend in our study. The cells in small fibroids enlarge during pregnancy and shrink in late pregnancy. The decrease in size observed in late pregnancy, by some studies, could be explained in part by the decrease in cell size. Myoma cells have a greater number of estrogen receptors than surrounding normal myometrial cells. ${ }^{3}$ Therefore, these cells are more responsive to the increased concentration of estrogen (estrogen surge) during pregnancy and exceed the growth of the surrounding myometrium. Progesterone on the other hand may inhibit the growth of fibroids and even induce degenerative changes and involution ${ }^{21-22}$. The increasing progesterone level in late pregnancy could explain the decrease in fibroid size during that period. Another theory implicates decreased arterial supply to fibroid as a cause of degeneration and decrease in size. ${ }^{23}$ The implications of this growth pattern are complications of pregnancy which may be based on the number, location and size of the myoma.
In the present study, fibroids were associated with obstetric complications such as bleeding, abortion and intra uterine growth restriction (IUGR). These findings corroborated the result obtained in Germany by Aydeniz et $\mathrm{al}^{24}$. In this present study, no placenta abruption was observed. Rice et $\mathrm{al}^{25}$ reported that pain and preterm birth correlated positively with the size of myoma. Vergani et $a^{26}$ reported that caesarean section (CS) was more common in women with myoma than the general population of parturient. They opined that CS was significantly higher in cases of myoma in the lower uterine segment compared with myoma at the fundus and, that CS was performed more when mean diameter of myoma exceeds $5 \mathrm{~cm}$. Batoniak et $\mathrm{al}^{4}$ also reported similar findings that increased incidence of preterm birth were observed in patients with uterine myoma larger than $600 \mathrm{~cm}^{3}$. Our study shows that a significant number of pregnant women with myoma had caesarean section (CS). Majority of cases in which myoma size was between $61 \mathrm{~mm}$ and $100 \mathrm{~mm}$ and $>100 \mathrm{~mm}$ resulted in CS. It can therefore be deduced from this study that large fibroids constitute greater risk of CS than small ones.

The commonest obstetric complication in patients with myoma in this study was abortion. This could be attributed to the number, location/type and size of the myomas. Jabiry-zieniewicz and Gajewska ${ }^{27}$ did a study on the outcome of pregnancy with myoma and concluded that abortion was the most eventful amongst other outcomes. The second commonest complication in subjects with myoma noted in this study was the syndrome of painful myomas, sometimes associated with bleeding, and probably related to haemorrhagic degeneration or infarction. Although the aetiology of the syndrome of painful myomas of pregnancy is rather unclear, high concentrations of progesterone, as in pregnancy, may play a role, as similar changes of "red degeneration" have been induced by highdosage progestin therapy. ${ }^{22}$ Pain was also noted in the group without myomas but in smaller number of subjects. Our study also showed that the complications such as abortion, pelvic pains, malpresentation and preterm delivery were seen to be more prevalent in patients with myomas than those without myomas. Caesarean section was performed more in subjects with myomas than those without myomas.

This study met with some difficulties while being conducted. Difficulty was encountered during measurement of very large fibroids in the third 
trimester. Measurement of fibroids in the same plane in subsequent scans was a challenge and the subjects under study reduced in number from 100 in the first and second scan sequences to 85 in the third scan sequence due to abortion. The findings in this study should be considered with these imposed limitations and difficulties taken into consideration.

\section{Conclusion}

Fibroids co-existing with pregnancy grow at the rate of $0.667 \mathrm{~mm}$ per week especially from first trimester to second trimester. The occurrence of myoma in pregnancy was $12.3 \%$ and was found to be commoner in older parturients. Myomas co-existing with pregnancy contribute a high percentage of obstetric complications and these complications are more with increasing myoma size.

\section{Recommendations}

Routine ultrasound scan is recommended to all pregnant women and should be performed carefully between 18 to 22 weeks gestation.

Sonography of pregnant patients with co-existing myomas should aim at:

Confirming presence of myoma.

Location of myoma in the uterus and relationship with the placenta.

Number and size of the myomas.

Scanning of the entire abdomen/pelvis for any associated lesions.

This would serve to identify pregnant women at risk for myoma-related complications and how best they can be managed.

Follow-up scans are recommended to determine any change in size of myoma as the pregnancy progresses.

\section{References}

1. Tsuda F, Gross B. Clinical predictors in the natural history of uterine leiomyomas; Preliminary study. J Ultrasound Med.2004; 17:1720.

2. Flake GP, Andersen J, Dixon D. Etiology and pathogenesis of uterine leiomyomas: a review. Environ Health Perspect.2003; 111:10371054.

3. Baird DD, Schectman JM, Dixon D, Sandler DP, Hill MC. African- Americans at higher risk than whites for uterine fibroids: ultrasound evidence. Am J Epidemiol.2002; 147:S90.

4. Batoniak B, $\mathrm{S}^{3}$ omko Z, Malewski Z, Drews K. The incidence of uterine leiomyomas in pregnancy and their influence upon its course. Ginekologie Poland 2002;73(4):260-5.

5. Pritts EA. Fibroids and infertility: a systematic review of the evidence. Obstet Gynecol Surveil 2001; 56: 483-491.

6. Chiaffarino F, Parazzini F, La Vecchia C, Chatenoud L, Di CintioE, Marsico S. Diet and uterine myomas. Obstet Gynecol.2004; 94:395398.

7. Cooper NP, Okolo S. Fibroids in pregnancyCommon but poorly understood. Obstet Gynecol Surveil.2005; 60: 132-138.

8. Parazzini F, Negri E, La Vecchia C, Chatenoud L, Ricci E, Guarnerio P. Reproductive factors and risk of uterine fibroids. Epidemiol. 2006; $7: 440-442$.

9. Ratner H. Risk factors for uterine fibroids: reduced risk associated with oral contraceptives. British Medical Journal 2006; 293:1027.

10. Neilson E, Mark C. Assessment of early routine ultrasound examination in the detection of fetal abnormality. J Ultrasound Med. 2010; 12:151-156.

11. Dueholm M, Lundorf E, Hansen ES, Ledertoug S, Olesen F. Evaluation of the uterine cavity with magnetic resonance imaging, transvaginal sonography, hysterosonogaphic examination, and diagnostic hysteroscopy. Fertil Steril. 2001; 76: 350 - 357.

12. Vollenhoven BJ, Lawrence AS, Healy DL. Uterine fibroids: a clinical review. British J Obstet Gynecol. 2000; 97:285-298.

13. Bosev D, Dimitrov A. Changes in uterine myoma dimensions during pregnancy. Akusherstvoi Ginekologiia (Sofiia). 2007; 46(5):36.

14. Exacoustos C, Rosati P. Ultrasound diagnosis of uterine myomas and complications in pregnancy. Obstet Gynecol. 2003; 82(1):97-101.

15. Govan, Macfarlane, Callander. Pathology Illustrated. Churchill Living Stone: London. $2^{\text {nd }}$ edition. 2002; pp 687- 694.

16. Gross B, Fleischer A. Sonographic features of uterine leiomyomas: Analysis of 41 proven cases. J Ultrasound Med. 2003; 2: 401-405.

17. Aharoni A, Reiter A, Golan D, Paltiely Y, Sharf $M$. Patterns of growth of uterine leiomyomas during pregnancy: a prospective longitudinal study. British J Obstet Gynecol. 2003; 100:510-3. 
18. Muram D. Samir F, Abdel A. Myomas of the uterus in pregnancy. Ultrasound follow- up. $A m$ J Obstet Gynecol. 2003; 138:16-19.

19. Neiger R, Sonek JD, Croom CS, Ventolini G. Pregnancy-related changes in the size of uterine leiomyomas. J Reprod Med. 2006; 51(9):671- 4.

20. Lamb JE, Abdel A. Microscopic study of the growth of leiomyomas of the uterus during pregnancy. Surg Gynecol Obstet. 2008; 108:575581.

21. Goldzieher JW, Maqueo M, Ricaud L, Aguilar JA, Canales E. Induction of degenerative changes in uterine myomas by high-dosage progestin therapy. American J Obstet Gynecol. 2002; 96:1078-1087.

22. Goodman AI. Samir F. Progesterone therapy in uterine fibromyomata. J Clin Endocrinol Metab. 2006; 6:402-408.
23. Sampson JA. Mohamed K. The blood supply of uterine myomata. Gynecol Obstet. 2002; 14:215-230.

24. Aydeniz B, Wallwiener D, Kocer C, Grischke EM, Diel IJ, Sohn C, Bastert G. Significance of myoma-induced complications in pregnancy. A comparative analysis of pregnancy course with and without myoma involvement. Zeitschrift Geburtshilfe Neonatologie. 2008; 202(4):154-8.

25. Rice JP, Kay HH, Mahony BS. The clinical significance of uterine leiomyomas in pregnancy. Am J Obstet Gynecol. 2000; 160(5 Pt 1):1212- 6.

26. Vergani P, Locatelli A, Ghidini A, Andreani M, Sala F, Pezzullo JC . Large uterine leiomyomata and risk of cesarean delivery. Obstet Gynecol. 2007; 109 (2 Pt 1): 410-414.

27. Jabiry-Zieniewicz Z, Gajewska M. The pregnancy and delivery course with pregnant women with uterine myomas. Ginekologiia Poland. 2002; 73(4):271-5. 